\title{
Analysis of epistemological congruence in Final Works of Concentration UCAB Guayana
}

DOI: $10.46932 / \mathrm{sfjdv} 3 \mathrm{n} 1-062$

Received in: Jan 30st, 2021

Accepted in: Feb 1th, 2022

\author{
Gilberto Resplandor Barreto \\ Doctor of Education \\ Center for Regional Studies \\ Universidad Católica Andrés Bello - Guayana \\ Prolongación avenida Atlántico Puerto Ordaz, estado Bolívar-Venezuela \\ E-mail: gresplan@ucab.edu.ve \\ Dr. Jesús Medina Maldonado \\ Doctor of Education \\ Center for Regional Studies \\ Universidad Católica Andrés Bello - Guayana \\ Prolongación avenida Atlántico Puerto Ordaz, estado Bolívar-Venezuela \\ E-mail: jmedina@ucab.edu.ve
}

\begin{abstract}
This documentary research has had 56 Final Concentration Works as references, prepared by the students of Social Communication from the UCAB (extension Guayana) in the academic periods 2017-2018 and 2018-2019, which are a requirement to qualify for the degree. An analysis of their philosophical congruence related to ontological, epistemological and methodological perspectives was performed. The dynamics were developed in several stages: first the 97 TFCs, that are stored in the University Library, were reviewed; secondly, the work was classified according to the methodology used. 56 reports were obtained under the qualitative methodology, in which the phenomenological and hermeneutic methods prevailed. The analysis carried out through a matrix developed for this purpose, showed that the lack of knowledge related to the principles and characteristics of the qualitative paradigm, this led to the approach of objectives far from the purposes of this type of research by not assessing the nature of the object of study in its just dimension. While there is coherence between the research question, the overall objective and the specific objectives, the reports, in this first part, are associated with the quantitative methodology more than the qualitative methodology. The lack of theoretical support represented for the most part by the background of the research and some basic definitions did not allow the theoretical-praxis contrast typical of this type of research. The gaps highlighted in the methodological approach leave clear evidence of a great weakness by not clarifying in detail the design of the research, presenting a procedure that did not specify how the data was obtained and how it was analyzed. As a product of the analysis carried out, it is concluded that the reports submitted do not have philosophical consistency in the absence of correspondence between the perspectives considered.
\end{abstract}

Keywords: Philosophical congruence, ontological, epistemological and methodological perspectives. 


\title{
1 INTRODUCTION
}

The Universidad Católica Andrés Bello (UCAB) is a Venezuelan higher education institution whose foundation was decreed by the Venezuelan Episcopate in 1951 and created on October 24, 1953; its headquarters are located in the city of Caracas and currently has offices in Los Teques (Miranda state) and Puerto Ordaz (Bolivar state). It is part of the universities entrusted to the Society of Jesus and is run by Jesuit priests.

Among its objectives, it proposes that:

\begin{abstract}
... should perform a leading role in education, culture and science. To accomplish this mission, its activities will be directed to create, assimilate and disseminate knowledge through research and teaching; to complete the comprehensive training initiated in previous educational cycles, and to form the professional and technical teams that the Nation needs for its development and progress. (UCAB Objectives, 2020, paragraph. 3)
\end{abstract}

Since its founding the UCAB has been dedicated to training professionals with a strong understanding of humanism, a high academic quality whose motto focuses on excellence and promotes the ignatian maxim of "all love and servitude for the greatest glory of God."

The Ucab, within its Institutional Training Project (2013), declares that its curriculum development model focuses on the competence approach and focuses on the development of general and professional competences that are operationalized in the execution of the different curriculum units throughout the course of university life within the career, where the elaboration and delivery of undergraduate work is also contemplated as requirements for obtaining the corresponding degree, in $90 \%$ of the careers it offers.

Within the general competences, it highlights the research capacity as a basic ability, which in turn constitutes the foundation that allows the subject to build its training around this process. The addition of research-related subjects in curriculums should aim at teaching and subsequently learning strategies, to learn how to research and not teach research, so that students are able to apply them in the professional fields where they will have to interact.

For Lombeida, 2019 (c-p Cabrera Rollin, 2020), research is a primary function of every college, actions that go hand in hand with the progress and development of each nation... To this end, "higher education through research seeks among its purposes to manifest new scientific knowledge, in order to respond in the development of humanity" (p. 86).

Research is learned by researching, so it's essential that research apprentices receive training that allows them, at the beginning of the implementation of the research process, to recognize from the beginning from which paradigm(s) the approach to reality is perceived, in the context of the discipline that is mediating the approach. 
In this sense research is always linked to reality, to the field of disciplinary knowledge of application, to the cultural, social and political context in which it develops and becomes the source of free and useful generation of thought, whose dissemination approximates scientists from different disciplinary fields, enriches university training and guides relevant social actors. (Behar Rivero, 2008, p. 14)

The different paradigms, according to Guba and Lincoln, 1985 (c.p. Sabariego Puig, 2009) differ into three basic issues: (a) the ontological, as a way of perceiving and conceiving reality; (b) the epistemological, assumed as the model of relationship between the subject investigating and the object of study and, (c) the methodological, understood as how to gain knowledge of reality.

For Gonzalez (2008), the paradigm becomes the polar star of the scientist, this affirmation becomes relevant with beginner researchers, because the inception of cognitive and procedural structures is necessary to address with relative success a research process.

A paradigm has a normative nature with respect to the technical and methodological aspects to be used. The belief of the research community on how to see reality entails a coherent position in the epistemological dimensions (in the way reality is approached) and methodological (in the way of knowing and interpreting it).) (Sabariego Puig, 2009, p. 67)

Triviño and Sanhueza (2005), argue that the main universally accepted paradigms are two, the quantitative, logical positivist or empirical analytical paradigm and the qualitative, symbolic, substantial, interpretive, historical and dialectical paradigm. These are the two approaches that, as content, are contemplated in the Methodology program to be taken by students of Social Communication of the UCAB.

One of the careers offered by the UCAB is the bachelor's degree in Social Communication, which lasts for 10 semesters. The School of Social Communication's curriculum consists of a basic cycle (six semesters) and two concentrations, eligible among seven options: Corporate Communications, Integrated Marketing Communications, Audiovisual Production, Screenplay, Scenic Production, Journalism and Cultural Management also, to graduate, it is mandatory to present and approve a Final Concentration Work (TFC), which could be the equivalent of a special undergraduate work, for each of the concentrations that the student takes, whose fundamental purpose is to demonstrate the acquisition of knowledge in the respective areas of specialization.

The TFC is conceived as the theoretical or theoretical-practical work that the student deploys under the guidance of a teacher, on a unique, delimited and feasible topic or problem to address from the skills acquired at the level of training; it aims to explore or describe a phenomenon or topic corresponding to a theoretical, methodological, instrumental, technical, practical or thematic dimension in the field of communication through a discursive genre of an academic nature typical of each concentration, it's monographic and compilatory in nature, and exhibits through the description a documentary (field) 
research, the development of a practical work or project and its scope will be determined on the basis of the following typologies: Feasible project, production projects, analysis projects and documentary research projects.

The TFC should be included within the lines of research proposed for each concentration or generate new lines for them, in addition it constitutes an academic product that represents the evaluation of a curriculum unit, and consequently the intellectual property of the same is shared with the University, its scope will be determined on the basis of the following typologies: Feasible project, production projects, analysis projects and documentary research projects.

\begin{abstract}
At the beginning of the 7th and 9th semesters, students select one of the concentrations mentioned before and during it, must submit to the school's TFC Committee a Project which is a document: that identifies and specifies the idea that constitutes the thematic area, research problem and study subject to be developed in this work. It also makes it possible to argue and determine the feasibility of the work, as well as to set out the theoretical bases (conceptual and referencing) that underpin the investigative proposal. (UCAB Regulation, 2017, apart 14)
\end{abstract}

This project, once approved, is implemented and presented over the course of the 8th and 10th semesters.

In the University Library, 97 Final Concentration Works remain, as of 30 July 2020, of which 56 $(57.73 \%)$ were developed under the qualitative paradigm. In the opinion of the researchers, as a product of the review and analysis of these TFCs it was determined that they have dissonance between the ontological, epistemological and methodological perspectives, which presumes that there is no philosophical congruence between the different sections that make up these works.

The above considerations led to conduct an analysis to show the lack of philosophical congruence (ontological, epistemological and methodological perspectives) between the different chapters of the TFCs, product of research carried out by the students of Social Communication of the UCAB Guayana, in the periods 2017-2018 and 2018-2019 with a view to incorporating some recommendations to improve the methodological approach in these research experiences.

\title{
2 MATERIALS AND METHODS
}

The thought to carry out the study arose in the researchers from the experience of tutoring students of Social Communication in the elaboration of their Final Concentration Works (TFC) and having participated as evaluators (jurors) of them, for four consecutive semesters, and, to note that, in general, the reports developed under the qualitative methodology, presented weaknesses and deficiencies related mainly to the mastery of how to proceed to develop research under this methodology. 
A documentary review of the TFCs resting in the University Library (97) was carried out, 56 TFC were selected for the analysis, which were developed under the qualitative methodology, as stated by the authors. To gather the information, a matrix (Annexed) was developed that allowed a series of related data to be extracted from each revised work, mainly with the first three chapters of the report, namely: Approach and formulation of the problem, Theoretical-referencing Framework and Methodological Framework.

For the construction of the matrix, the following aspects were considered: identification of the academic period, concentration, author(s), TFC title, problem, general objective and specific objectives, reference theoretical framework, approach, paradigm, design, method and steps for its application, key informants, techniques and instruments, procedures of analysis of the data and finally the coherence between the paradigm, objectives and methodological approach.

The dynamic for collecting data was to review all TFCs that rest in the University Library; classify work according to the methodology for its development; reading the summary, introduction and the chapters that make up the body of each report in order to complete the aspects contemplated in the matrix and finally the information was extracted to consolidate a summary of each work.

The analysis of the information obtained from each TFC was compared with theoretical aspects related mainly to "the ontological, epistemological and methodological perspectives of the qualitative paradigm" (Rojas de Escalona, 2014, p. 40). These perspectives bring together a set of criteria that identify them.

\section{RESULTS AND DISCUSSIONS}

According to Alvarez-Gayou (2003), it is not possible to investigate without paradigms. "The advent of the qualitative paradigm was a revolution in the field of scientific research, but its penetration has not displaced or eliminated the quantitative paradigm, nor will it eliminate it" (p. 30). It has been proven in a reliable way that the quantitative paradigm does not provide satisfactory answers to the diversity of problem situations that arise in the field of social sciences and their application to the study of these problems; in some higher education institutions, it can be appreciated more as a fashion than as an application of scientific methodology duly based from the mastery and knowledge of the design and methodologies of this way of knowing.

The nature of social problems requires an approach to the object of study from different perspectives, insofar as the qualitative methodology has principles and characteristics, called perspectives by some authors, which guide the way qualitative researchers act. 
The case at hand, the review and analysis of TFCs, research reports prepared by the students of Social Communication of the UCAB Guayana during the academic periods 2017-2018 and 2018-2019, allowed to show a set of situations that reveal, as a starting point, the lack of knowledge of what typifies this methodology.

According to Rojas de Escalona (2014), "Qualitative research is a way of conceiving reality, methods to address its study, as well as techniques and instruments in line with these methods and procedures of analysis and validation consistent with the theoretical foundations that underpin it" (p. 13), from the approach and formulation of the problem there must be consistency between the different sections of the work, in order for the information presented to have the validity that the results of the research problem developed with this methodology require.

Based on the classification proposed by Rojas de Escalona (2014) and Hernández, Fernández and Baptista (2014), the qualitative paradigm is classified according to the following criteria:

Table 1. Characteristics of the qualitative paradigm

\begin{tabular}{|l|l|}
\hline Denomination & $\begin{array}{l}\text { Phenomenological, Interpretative, Naturalistic, Understanding, Hermeneutic, } \\
\text { Subject-Centric }\end{array}$ \\
\hline Philosophical Base & Phenomenology \\
\hline Representatives & Edmund Husserl, Alfred Schutz \\
\hline Conception of reality & Complex, subjective, experiential, relative \\
\hline $\begin{array}{l}\text { Subject-to-object } \\
\text { relationship }\end{array}$ & $\begin{array}{l}\text { Interdependence. subjectivist. Social and human processes are explained by } \\
\text { subjects' interpretations of their own actions. }\end{array}$ \\
\hline Methodology & Basically qualitative \\
\hline Emphasis & Understanding, Description (Why?) \\
\hline Role of values & $\begin{array}{l}\text { The values of different actors in the research process are recognized and } \\
\text { emphasized }\end{array}$ \\
\hline $\begin{array}{l}\text { Theory-practical } \\
\text { relationship }\end{array}$ & The theory arises from the context studied \\
\hline Design & Emerging and flexible \\
\hline $\begin{array}{l}\text { Criteria for evaluating } \\
\text { research }\end{array}$ & Transferability, credibility, reliability, confirmability, utility. \\
\hline Logic & Applies inductive logic from the data to generalizations and theory \\
\hline Use of theory & Theory is a frame of reference \\
\hline Nature of the data & The nature of the data is qualitative: texts, narratives, meanings, among others. \\
\hline
\end{tabular}

Source: Rojas de Escalona (2014) and Hernández, Fernández y Baptista (2014), modified by the authors.

From the analysis carried out to Chapter I, The Problem, in the 56 TFCs there is no clarity as to the nature of the problem. A description of them is presented without delving into the specifying the context of the location, this situation departs from what should be an adequate description of a research problem developed with a qualitative methodology, since the particular is fundamental, uses inductive logic. 
All the work shows a connection between research questions and objectives and, between general and specific objectives, but these objectives depart from the goal of the qualitative methodology whose purpose is to understand the actions of the subjects.

21 TFCs of the Audiovisual Production concentration were identified. In this concentration the verbs for the drafting of the general objectives that prevailed were: to elaborate, perform, produce and analyze. Among the specific objectives the predominant verbs focused on: defining, characterizing, describing, establishing, studying, analyzing, mentioning, explaining, developing, defining, raising, comparing and segmenting.

Of TFC's total, 10 corresponded to the Integrated Marketing Communications concentration. The verbs for the general objectives are: to create and develop and, the specific objectives: to realize, characterize, develop, design, analyze, describe, determine and structure.

20 TFCs were identified with the Corporate Communications concentration. The verbs for the drafting of the general objectives were: to develop, perform, create, contrast and analyze. In specific objectives; determine, identify, create, develop, define, produce, compare, study.

Finally, 5 TFCs were presented at the Journalism concentration, whose verbs for the drafting of the general objectives were: to elaborate and present. Specific objectives: describe, reflect and to know.

Qualitative research is fundamentally interpretative, so the objectives should be in line with the research approach, "its focus is on the description, analysis and interpretation that lead to the understanding of the reality under study" (Rojas de Escalona, 2014, p. 69), so that researchers, once the concentration has been identified, the research topic located and the problem described, the questions asked and the approach chosen that will guide the study, must analyze in detail the theoretical assumptions of that approach to draft its objectives in accordance with them, not addressing this situation with due care to creates the illusion of developing a qualitative research when in fact, by the way of describing the problem and drafting the objectives, they are located in the quantitative paradigm.

The objectives are at the heart of any investigation, so their approach is the most important phase of the research process (Sierra, 2018)

Barrier Hurting expressed (2008) that the overall objective guides where the study is headed, while the specific objectives are the actions to be taken to achieve the overall objective. In drafting the objectives, care should be taken to use the words that best fit the purpose of the research, as this facilitates the selection of corresponding methodological procedures with the nature of the object of study.

A compilation of several authors, including Hernández, Fernández and Baptista (2010); Hurtado y Toro (1998); Martínez M (2006); Perez (2000); Rodriguez, Gil and Garcia (1999); Rojas (2007); Rusque (1999); Vasilachis (2007); Tarrés (2001) and Ochoa (2013), conducted by Rosales (2017) 
managed to consolidate a list of appropriate verbs for the development of qualitative research, among which it is worth mentioning: understand, deduce, find, discover, apprehend, derive, conclude, interpret, relate, glimpse, perceive, transform, build, deconstruct, develop, organize, clear out, elucidate, unravel, to find out, point out.

On the other hand, Arias (2001) suggests that for the drafting of objectives in qualitative research, verbs such as interpreting, understanding, unveiling, resignifying, exploring, describing, diagnosing and inquire should be used.

According to Leal (2011), the objectives encompass the achievements to be accomplished in the research process, so for its formation it must be considered the ultimate purpose of the current or approach that guides the study: either explain or control reality, understand or seek out the meaning of the phenomenon, transform existing practices or build knowledge. For example, if research is framed in the interpretative paradigm "it is incongruous to talk about determining, establishing or measuring, because what the researcher seeks is not to control reality but to understand it, therefore actions have to be oriented towards that purpose; to have a comprehensive vision."' (p. 56)

In this order it's recommends using verbs such as understanding, interpreting, showing, search, generating, relating, exploring, comparing or contrasting, Reflecting, visualizing, and feeling.

From the considerations set out above, and in accordance with what was indicated by Leal (2011), "one of the difficulties seen in the research reports is the lack of coherence in the discourse between the epistemic current that guides it, the approach to the problem, the drafting of the objectives and the methodology..."(p. 57).

Of the 56 TFCs explored, $100 \%$ refer to at least three previous works as background references and basic definitions; only $24 \%$ presents a development of the theoretical reference framework according to the requirements of the TFC Regulations which states that this part will include a preliminary version of the theoretical-conceptual sustenance and information relating to the subject matter of study in a descriptive way for evaluation prior to the approval of the project, must consist of: (a) Background references; (b) Definition of basic terms; (c) Description of theories or base authors of the research and (d) Description of the object of study. $76 \%$ of reports do not provide theoretical development.

In qualitative research, it is desirable to build the state of art, according to Guevara (2016): "it is the first moment in the development of research" (p. 170) constitutes the Referencing Framework of it and gives an account of the state of progress of the research.

The initial stage of the research is the exploration of investigative production on art states related to the subject of study, to examine the background references of the problem to be studied and to have context on the progress that has been made in this field. The state of the art feeds the theoretical framework 
that clarifies the concepts from which explanations in research are addressed. In the concept of the state of art as research, the first approach becomes a fundamental element in the development of the inquiry itself.

This lack of information does not allow the contrast between theory and research findings, so there is no possibility of theory generation in the light of such confrontations.

With regard to the methodological framework, all the TFCs studied begin with a definition of the research or qualitative methodology. Reference is made to definitions provided by Hernández, Fernández and Baptista (2010), Albert (2009), Hernández (2003), Sandín (2003). There is no clarification about the assumed epistemological approach or framework, an aspect that is relevant in the research carried out under the interpretative paradigm.

Regarding the tradition or qualitative approach assumed as a method, 57.14\% were developed with the phenomenological method or phenomenological design; $37.5 \%$ were carried out using the hermeneutical method and 5.35\% were life stories. It should be noted that none of the TFCs considered it relevant to specify the phases or stages of application of the methods used.

The notion of key informants is used to identify the sources from which the information was obtained, but the criteria for their selection are not clarified, this section is similar to the selection of an intentional sample without major contributions.

The techniques and instruments used to obtain the data correspond to those used in the qualitative methodology. It is stated that observation and interview were the techniques used and as instruments are semi-structured interviews, interview scripts, observation guides, voice recorders and field notes.

None of the papers provide information about the analysis procedure followed for the data analysis. The confirmation of the information obtained through the socialization of the results of the analyses carried out nor the use of triangulation as a tool for verification is proposed.

The weaknesses observed in the methodological approach to the research entail a series of flaws that make us presume a lack of knowledge of how to approach this type of problematic situation and present research reports that correspond to results according to the type of paradigm assumed.

\section{CONCLUSIONS}

As a result of the review and analysis of the 56 TFCs identified as carried out under the qualitative paradigm, it is concluded that from the approach and formulation of the problem and the statement of the objectives, both general and specific, there is already dissonance between the latter and the interpretative paradigm, since the intention to understand and interpret the actions of the different participating actors as co-investigators is not contemplated in any of the studies. 
As there is no theoretical support, except what is reported in the background references of the investigations, the contrast phase cannot be carried out in the analysis, so the production of new knowledge is not present as a result of the investigations.

The fact that the methodological approach is presented with the aforementioned weaknesses suggests that data collection is carried out in an unsystematic way, without the rigor required to obtain valid and reliable results, which represent true contributions to knowledge in each of the groups of subjects that make up each concentration of studies.

Based on the analysis shown, it is finally concluded that the TFCs developed under the qualitative paradigm do not present philosophical congruence between the different parts of the report, since it does not describe in detail the context of location of the problem situations and the object of study It lacks characterization, this situation means that the objectives do not correspond to the assumed paradigmatic approach. The gnoseological contributions are absent, that is, there is no theoretical support and the weakness evidenced in the methodological approach reduces validity and relevance to the final products obtained. 


\section{REFERENCES}

Álvarez-Gayou, J.L. (2003). How to do qualitative research. Fundamentals and methodology. Barcelona, Spain: Paidós

Arias, F. (2001). Myths and errors in the development of research projects. 2nd edition. Caracas: Episteme Bahar Rivero, D. (2008). Investigation methodology. Argentina: Shalom Editions

Cabrera Rollin, W.O, (2020). Importance of research in higher education for the contribution to scientific knowledge and the development of society. In Why is it important to teach research? Matías Denis (Compiler). Encarnacion, Paraguay: Divesper

González, F. E. (2008). Notes for a Pentadimensional Critique of Socioeducational Research. Educação em Questão Magazine, Natal, v. 32, n. 18, p. 40-78, May / Aug. 2008

Guevara, R. (2016). The state of the art in research: analysis of accumulated knowledge or search for new meanings? Folios Magazine, no. 44, July-December, 2016, pp. 165-179 National Pedagogical University Bogotá, Colombia

Hernández, R .; Fernández, C. and Baptista, P. (2014). Investigation methodology. 6th edition. Mexico: Mc Graw-Hill Interamericana

Hurtado de Barrera, J. (2008). Holistic research methodology. Caracas: Sypal Foundation

Leal, J. (2011). The autonomy of the research subject and the research methodology. 3rd edition. Valencia, Venezuela: Intense Blue impressions

Ochoa, C. (2013). Verbs in qualitative research. Central University of Venezuela. Caracas.

Rojas de Escalona, B. (2014). Qualitative research. Fundamentals and praxis. 3rd edition. Caracas: FEDUPEL

Rosales, A. (2017). Verbs for qualitative research. Compilation of various authors. Ucab Guayana, School of Social Communication

Sabariego Puig, M. (2009). Educational Research. Genesis, Evolution and Characteristics in Educational Research Methodology. Bisquerra Alzina, R. (Coordinator). 2nd edition. Madrid: La Muralla, S.A.

Triviño, Z. and Sanhueza, O. (2005). Nursing Research Paradigms. SCIENCE AND NURSING XI (1): 17-24, 2005. https://scielo.conicyt.cl/pdf/cienf/v11n1/art03.pdf

UCAB (2020). Institutional information about the University. Available: https://www.ucab.edu.ve/informacion-institucional/acerca-de-la-universidad/

UCAB (2017). School of Social Communication. Current regulations for final concentration works. Available: http://w2.ucab.edu.ve/tl_files/Escuela_com_social/201725/NORMATIVA\%20TFC.pdf

UCAB (2013). Institutional Training Project. Recovered: https://issuu.com/lacatolica/docs/pfi-ucab 